\title{
Thermoplastic Starch-Based Blends with Improved Thermal and Thermomechanical Properties
}

\author{
Anayansi Estrada-Monje ${ }^{1, *}$, Sergio Alonso-Romero ${ }^{1}$, Roberto Zitzumbo-Guzmán ${ }^{1}$, \\ Iván Alziri Estrada-Moreno ${ }^{2}$ (D) and Erasto Armando Zaragoza-Contreras ${ }^{2, *}$ (D) \\ 1 Centro de Innovación Aplicada en Tecnologías Competitivas, A.C. Calle Omega No. 201, Industrial Delta, \\ León C.P. 37545, Mexico; salonso@ciatec.mx (S.A.-R.); rzitzumbo@ciatec.mx (R.Z.-G.) \\ 2 Centro de Investigación en Materiales Avanzados, S.C. Miguel de Cervantes No. 120, Complejo Industrial \\ Chihuahua, Chihuahua C.P. 31136, Mexico; ivan.estrada@cimav.edu.mx \\ * Correspondence: aestrada@ciatec.mx (A.E.-M.); armando.zaragoza@cimav.edu.mx (E.A.Z.-C.); \\ Tel.: +52-4777100011 (A.E.-M.); +52-6144391100 (E.A.Z.-C.)
}

check for

updates

Citation: Estrada-Monje, A.; AlonsoRomero, S.; Zitzumbo-Guzmán, R.; Estrada-Moreno, I.A.; ZaragozaContreras, E.A. Thermoplastic Starch-Based Blends with Improved Thermal and Thermomechanical Properties. Polymers 2021, 13, 4263. https://doi.org/10.3390/ polym 13234263

Academic Editor: De Feng Wu

Received: 23 September 2021

Accepted: 25 October 2021

Published: 6 December 2021

Publisher's Note: MDPI stays neutral with regard to jurisdictional claims in published maps and institutional affiliations.

Copyright: (c) 2021 by the authors. Licensee MDPI, Basel, Switzerland. This article is an open access article distributed under the terms and conditions of the Creative Commons Attribution (CC BY) license (https:// creativecommons.org/licenses/by/ $4.0 /)$.

\begin{abstract}
This research focused on the development of biomaterials based on cassava starch and corn starch and on the effect of the incorporation of polycaprolactone (PCL) on the thermal and thermomechanical properties of the blends. The results indicated partial compatibility in the blends, especially with cassava starch at a content of $20 \mathrm{wt} \%$ as reflected by the maintenance of tensile strength and elongation. In addition, the changes in the crystal quality of PCL and the displacement of the absorption bands of the carbonyl groups of PCL in the infrared (989-1000 cm ${ }^{-1}$ ), attributed to the formation of hydrogen bonds between these groups and the hydroxyl groups of starches, were also associated with compatibility. It was observed that the crystallinity of PLC in the presence of cassava and corn starch was $38 \%$ and $62 \%$, respectively; a crystallinity greater than that of PCL was related to an improved nucleation at the interface. Based on these properties, the blends are expected to be functional for the manufacture of short-term use products by conventional thermoplastic processing methods.
\end{abstract}

Keywords: biobased blend; cassava starch; corn starch; polycaprolactone; thermoplastic starch

\section{Introduction}

Plastics derived from petroleum have contributed to increasing the comfort of people's everyday lives due to the notable versatility of properties that allows for the manufacturing of an infinite number of products. However, poor waste management and the lack of a culture of efficient recycling generate pollution that affects both terrestrial and marine ecosystems due to the accumulation of non-biodegradable plastic waste. For this reason, at the 4th United Nations Environment Assembly, a global agreement to reduce the consumption of non-biodegradable single-use plastics, was established [1]. With the growing need to take care of the environment and to find alternative materials that are more ecological for manufacturing short-term use products, research and development in biodegradable and bioplastic polymers has emerged [2].

Once in the environment, biomaterials biodegrade under the action of the weather and microorganisms [3]. The biodegradation products are carbon dioxide, methane, water, biomass, and several other harmless substances that are incorporated into the soil [4]. For example, the development of spoons made with biodegradable materials from seed flour, xanthan gum, and palm oil was performed as an alternative to the use of plastic cutlery [5].

Starches are essential raw materials for the development of biobased blends and composites, as they are natural and abundant biopolymers that come from grains such as corn, cassava, potato, rice, and others [6]. Native starch consists of two chemically different polysaccharides: amylose and amylopectin [7]. The former is a linear polymer composed of glucose units linked by $\alpha(1-4)$ bonds; despite some $\alpha(1-6)$ bonds that may be present, it 
is not water-soluble. The latter is a branched polymer of glucose units that are $95 \%$ linked by $\alpha(1-4)$ bonds, which is partially soluble in hot water [8]. According to Bertolini et al. [9], starches differ from each other by their amylose and amylopectin content, depending on the source of origin. García et al. [10] reported that the higher the amylopectin content, the higher the crystallinity in starches. For example, cassava starch is $17 \%$ amylose and $83 \%$ amylopectin, while maize starch is $28 \%$ amylose and $72 \%$ amylopectin [8]. Native starch has no plastic properties; however, when subjected to stress, under the action of temperature and in the presence of a plasticizer, a thermoplastic starch (TPS) can be obtained [11]. A TPS is meltable and processable by conventional processing methods. The plasticizer breaks the strong intramolecular interactions forming hydrogen bonds with the starch, resulting in plasticization [12]. Water, glycerol, sorbitol, sugar, ionic liquids, and compounds that have functional groups such as urea, formaldehyde, anhydride, or acetamide are applicable as plasticizers [13-17]. Although TPSs are biodegradable, they have poor mechanical properties and high susceptibility to water that restrict their use in many applications. One way to overcome these drawbacks is by blending with another biodegradable polymer that improves the mechanical properties of the final blend. Cellulose nanofibers and poly(vinyl alcohol) crosslinked with borax were used to improve the mechanical properties of starch for food packaging design [18]. Lactic polyacid has also been used in combination with starch, using hemp oil modified with maleic anhydride as plasticizer and compatibilizer. The added plasticizer showed improvements in the blend ductility and impact resistance [19]. Chitosan has also been used as a dispersed phase in TPS, incorporating it by thermomechanical methods and without the addition of compatibilizer. The addition of chitosan was found to considerably increase the Young's modulus and tensile strength [20]. The addition of inorganic compounds for the mechanical reinforcement of TPS has also been reported. The addition of dolomite in a range of $1-5 \mathrm{wt} \%$ showed a better performance of tensile strength and Young's modulus, especially for the higher inorganic contents. Better dispersion of the particles was also found to improve mechanical performance [21].

Polycaprolactone (PCL), a semi-crystalline and biodegradable thermoplastic characterized by its high flexibility, low melting point, and high compatibility with other polymers, has been explored to modify TPS [22,23]. For example, for a TPS plasticized with glycerol, it is possible to increase the blend's hydrophobicity by incorporating PCL [24]. These types of blends have been studied for the improvement of their mechanical and thermal properties [13]. Cassava starch and PCL films, in the presence of an antioxidant, showed that the thermal properties of TPS were affected, which was interpreted as partial compatibility between polymers; however, tensile stress was reduced by $6 \%$ with the incorporation of PCL [25]. In another work, with the cassava starch-PCL blend, it was observed that the incorporation of PCL generated immiscibility, forming systems with starch as a dispersed phase, observed by electron microscopy. Furthermore, the addition of the PCL caused an increase in the elastic modulus and tensile stress at a relative humidity of 54\% [26]. Considering the difficulties in integrating thermoplastic starch-PCL blends due to the polarity differences, the grafting of PCL on starch has been used. The grafting of the PCL was manifested as an increase in the flexibility of the TPS, without detriment to the biodegradability [27].

It is worth saying that although there are some studies dedicated to blends of PCL with TPS, there is still a lack of information on the properties of such blends and the analysis of their molecular interactions, so it is possible to improve the interfacial compatibility between the polymeric phases to improve the thermal and thermomechanical properties. Consequently, there is ample opportunity to contribute new knowledge on this topic. In this work, we investigated whether the type of starch (i.e., corn or cassava) influenced the generation of the best interaction towards a blend with improved properties without the use of coupling agents. We found evidence of the formation of an amylose-glycerol complex in blends with cornstarch, suggesting strong interactions between amylose and glycerol. The literature suggests that two opposite processes coexisted simultaneously in 
the blends: retrogradation, which stiffens the material, and plasticization, which softens it, with the latter mechanism predominating at short times and reversing at longer times. Moreover, there was evidence that the incorporation of PCL delays the retrodegradation, expanding the applications of the blend. It is important to highlight that conventional plastics transformation processes allow for exploring the possible applications of biomaterials to promote the use of ecological plastics, for example, in disposable plates and single-use cutlery.

\section{Materials and Methods}

\subsection{Materials}

Cassava starch (CaS) and corn starch (MaS) (Best Ingredients Mexico, Santa Catarina, Mexico), polycaprolactone (CAPA 6506, TRiiSO, Cardiff, CA, USA), and glycerol (CTR Scientific, Monterrey, Mexico) were used in the experimentation. All reagents were used as received.

\subsection{Blend Processing}

CaS and MaS plasticized with glycerol, hereinafter referred to as CaPS and MaPS, respectively, were prepared by manual mixing as follows: $70 \mathrm{wt} \%$ native starch and $30 \mathrm{wt} \%$ glycerol. Each system was fed into a twin-screw extruder (Micro27, Leistritz, Nuremberg, Germany) with an L/D of 32:1. The screw speed was $80 \mathrm{rpm}$, and the temperature profile was $110,110,120,120,130,120$, and $110^{\circ} \mathrm{C}$. The filaments obtained were air-cooled and pelletized.

Subsequently, the pellets of CaPS and MaPS were mixed with $20 \mathrm{wt} \%$ PCL. The blends were processed in the same twin-screw extruder at $80 \mathrm{rpm}$ and a temperature profile of 110 , $110,120,120,130,120$, and $110^{\circ} \mathrm{C}$. At the end of the process, the blends were pelletized and referred to as CaPS-PCL and MaPS-PCL.

Finally, the blends were injected to obtain Type 1 specimens according to the ASTM D638 procedure to evaluate the tensile strength and the percentage of elongation in universal traction equipment (model 5565 standard, Instron, Norwood, MA, USA).

\subsection{Characterization}

Functional groups were characterized using a Fourier-transform infrared spectrophotometer (Series 2 Magna IR 750, Thermo Fisher Nicolet, Waltham, MA, USA) in a wavenumber range of 4000-400 $\mathrm{cm}^{-1}$ with 16 scans and a resolution of $4 \mathrm{~cm}^{-1}$.

The glass transition temperature $(\mathrm{Tg})$ was determined using a differential scanning calorimeter (DSC, Pyris 1, Perkin-Elmer, Akron, OH, USA) under a nitrogen atmosphere, from room temperature to $200{ }^{\circ} \mathrm{C}$ at a heating rate of $10{ }^{\circ} \mathrm{C} \mathrm{min}-1$. The crystallinity index (CI) and the melting temperature of the PCL and blends were determined according to Equation (1) [28]:

$$
\mathrm{CI}(\%)=\left(\frac{\Delta \text { Hexp }}{\Delta \text { Hof }}\right) \times 100
$$

where $\Delta$ Hexp is the experimentally determined enthalpy of fusion $\left(\mathrm{J} \mathrm{g}^{-1}\right), \Delta \mathrm{Ho}$ is the theoretical enthalpy of fusion of fully crystalline PCL (132 J g $\left.{ }^{-1}\right)$ [29], and $\mathrm{f}$ is given by the weight percentage of PCL in the mix.

Thermograms were obtained on a thermogravimetric balance (Q500, TA Instruments, DE, USA) in the temperature range $40-700{ }^{\circ} \mathrm{C}$, with a heating rate of $10{ }^{\circ} \mathrm{C} \mathrm{min}-1$, a nitrogen purge flow of $20 \mathrm{~mL} \mathrm{~min}^{-1}$, and a sample of approximately $30 \mathrm{mg}$.

Dynamic mechanical analysis (RSA III, TA Instruments, New Castle, DE, USA) was achieved in the three-point mode at $1 \mathrm{~Hz}$. Temperature sweeps were performed in the range $-95-120{ }^{\circ} \mathrm{C}$ at a heating rate of $5{ }^{\circ} \mathrm{C} \mathrm{min}-1$. A strain of $0.1 \%$, within the linear viscoelastic range, was chosen. The sample dimensions were $40 \mathrm{~mm} \times 12 \mathrm{~mm} \times 2 \mathrm{~mm}$.

The mechanical properties were evaluated in universal tension equipment (model 5565 standard, Instron, MA, USA) according to the ASTM D-638 procedure. The tests were 


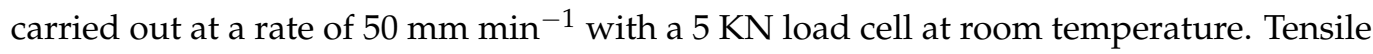
strength $\left(\sigma_{\max }\right)$ and elongation at break $(\varepsilon)$ were evaluated.

\subsection{Statistical Analysis}

The Statgraphics ${ }^{\circledR} 19$ (Centurion XVI, The Plains, VA, USA) software was used for the statistical treatment of the data. Through its application, it was possible to carry out a descriptive analysis of one or more variables, using graphs that explained their distribution, calculating their characteristic measures as well as the calculation of confidence intervals.

\section{Result}

\subsection{Analysis of Functional Groups}

Figure 1a,b illustrate the FTIR spectra of MaS and MaPS and CaS and CaPS, respectively. Absorption bands in the range of $992-1200 \mathrm{~cm}^{-1}$ in starches were associated with interactions between starch molecules and the plasticizers [30]. The spectra of CaPS and MaPS showed the presence of a new peak at 992 and $990 \mathrm{~cm}^{-1}$, respectively; while the absorption of C-C-O of the anhydroglucosidic ring showed no change $\left(988 \mathrm{~cm}^{-1}\right)$, which appeared in the unplasticized starches $\mathrm{MaS}$ and $\mathrm{CaS}$ [31]. Interestingly, there was no displacement of the band at $988 \mathrm{~cm}^{-1}$ of $\mathrm{C}-\mathrm{C}-\mathrm{O}$, but there was the formation of a new absorption, which Zullo et al. identified at approximately $1015 \mathrm{~cm}^{-1}$ [31], which suggests a new interaction as well as new modes of vibration after starch thermoplasticization.
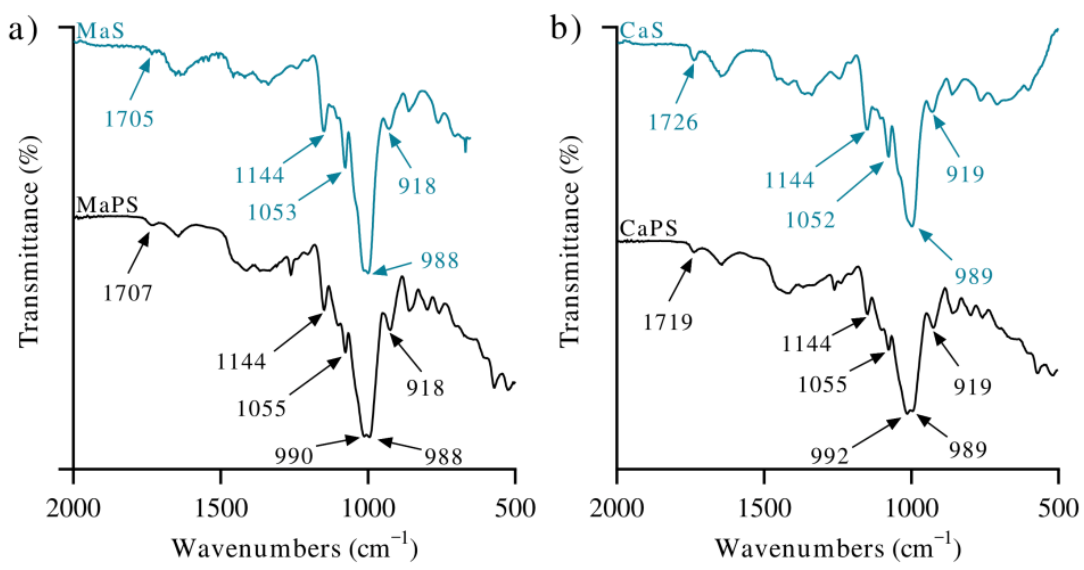

Figure 1. Infrared spectra of (a) native corn starch (MaS) and plasticized corn starch with $30 \mathrm{wt} \%$ glycerin (MaPS) and (b) native cassava starch (CaS) and plasticized cassava starch with $30 \mathrm{wt} \%$ glycerin (CaPS).

Another observation is that in $\mathrm{CaS}$, there was a peak at $1726 \mathrm{~cm}^{-1}$ that can be associated with carbonyl groups. This signal shifted to $1719 \mathrm{~cm}^{-1}$ for the plasticized starch. It is worth mentioning that this peak appeared at lower values in MaS. A carbonyl signal was not expected in either of the two native starches, since no carbonyl group was generated during glycerol plasticization. However, the presence of this small peak was attributed to a starch decomposition process, which did not affect its physicomechanical properties [32].

Likewise, there was also an increase in the intensity of the absorption at $3362 \mathrm{~cm}^{-1}$, corresponding to the stretching of $\mathrm{OH}$ in plasticized starch. Importantly, this band was outstanding when there were intermolecular interactions as in the case of plasticized starch [33]. The weakening of the covalent bond force in which the donor $\mathrm{H}$ participated [34] was an attributed cause.

In the spectrum of MaPS-PCL, peaks corresponding to the PCL (Table 1), such as the absorption for $\mathrm{C}=\mathrm{O}$, suggest an interaction between both materials, whereas the absorption for $\mathrm{OH}$ at $3316 \mathrm{~cm}^{-1}$, with high intensity, indicates hydrogen bonding and intermolecular interactions. The displacement of the band at $989 \mathrm{~cm}^{-1}$ for MaPS and $992 \mathrm{~cm}^{-1}$ for CaPS (Figure 2) to $998 \mathrm{~cm}^{-1}$ (MaPS-PCL) and $1000 \mathrm{~cm}^{-1}$ (CaPS-PCL), respectively, manifests the 
interaction between PCL and starch. The functional groups that formed hydrogen bonds may be responsible in both cases for such displacements.

Table 1. Band assignation in the FTIR spectra.

\begin{tabular}{|c|c|c|c|c|c|c|}
\hline \multirow{3}{*}{ Bonding } & \multicolumn{6}{|c|}{ Wavenumbers $\left(\mathrm{cm}^{-1}\right)$} \\
\hline & \multicolumn{2}{|c|}{ Experimental Values } & \multirow{2}{*}{ Mina et al. [33] } & \multirow{2}{*}{ PCL } & \multirow{2}{*}{ MaPS } & \multirow{2}{*}{ CaPS } \\
\hline & MaPS-PCL & CaPS-PCL & & & & \\
\hline O-H stretching & 3270 & 3270 & 3331 & & 3288 & 3270 \\
\hline $\begin{array}{l}\text { Asymmetric/symmetric } \\
\mathrm{CH}_{2} / \mathrm{CH}_{3}\end{array}$ & $2929 / 2872$ & $2930 / 2870$ & $2945 / 2866$ & $2942 / 2866$ & $2913 / 2887$ & $2920 / 2887$ \\
\hline $\begin{array}{c}\mathrm{C}=\mathrm{O} \text { Stretching } \\
(\mathrm{PCL})\end{array}$ & 1723 & 1724 & 1724 & 1718 & & \\
\hline $\begin{array}{c}\text { Asymmetric stretching } \\
\text { C-O-C (PCL) }\end{array}$ & 1242 & 1242 & 1242 & & 1242 & 1242 \\
\hline $\begin{array}{l}\text { Stretching of } \\
\text { Glycosidic C-O-C }\end{array}$ & 1055/1146 & $1059 / 1146$ & $1043 / 1029$ & & $1055 / 1144$ & $1055 / 1144$ \\
\hline Water absorption & 1622 & 1621 & & & 1618 & 1625 \\
\hline $\begin{array}{l}\text { Glycosidic bond, } \mathrm{C}-\mathrm{O} \\
\text { stretching }\end{array}$ & 989 & 989 & & & 988 & 989 \\
\hline After plasticization & 998 & 1000 & & & 990 & 992 \\
\hline
\end{tabular}

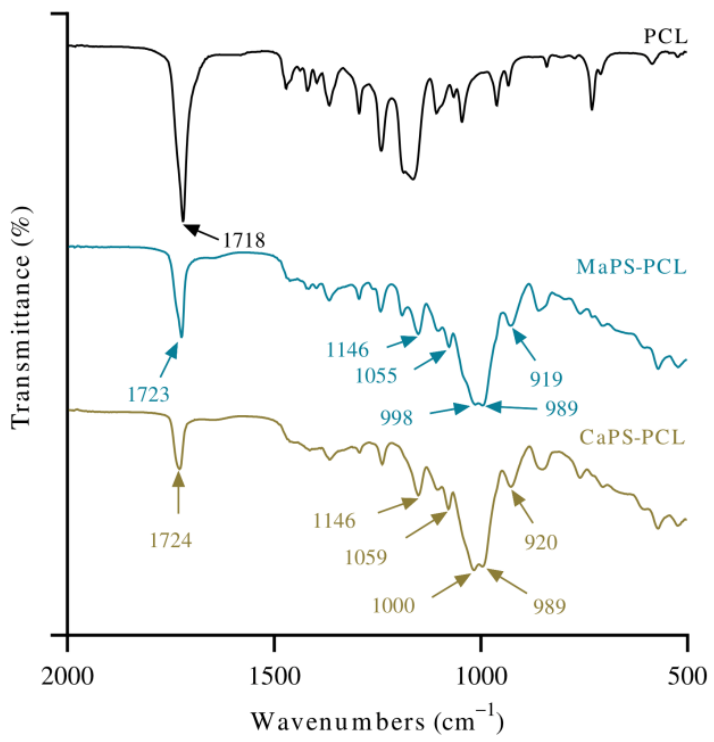

Figure 2. Infrared spectra of the blends CaPS-PCL and MaPS-PCL. PCL was included as a reference.

Mina et al. studied binary blends of plasticized cassava starch and PCL [33]. However, they used higher contents of PCL, finding poor miscibility between PCL and plasticized starch, evidenced by the lack of displacement in the absorption at $1723 \mathrm{~cm}^{-1}$ of PCL. Oppositely, at $20 \mathrm{wt} \% \mathrm{PCL}$, as in the present research, a displacement from $1718 \mathrm{~cm}^{-1}$ to $1724 \mathrm{~cm}^{-1}$ was found. This displacement raises the possibility of miscibility between the materials. Casteros reported the shift of infrared absorption bands with miscibility between polymers [34]. It is worth noting that some miscibility can arise in blends of starch and PCL because starch has proton donor groups (OH group) and PCL proton acceptor groups (carbonyl group) [26].

The shift in the carbonyl absorption was slightly more evident in CaPS-PCL, from 1718 to $1724 \mathrm{~cm}^{-1}$ (Figure 2), quite possibly because CaS contains more amylopectin than 
MaS. The functional groups that form hydrogen bonds may be more available in $\mathrm{CaS}$ as reported in the literature [8]. It has also been reported that in esters, the absorption of the carbonyl group presents a shift in the infrared absorption frequency when the group is associated [27].

\subsection{Glass Transition and Crystallinity}

DSC was used to identify the transition temperatures and crystallinity index. Figure 3 shows the thermograms of PCL, MaPS-PCL, and CaPS-PCL. As observed, the PCL presented an intense transition at $65.4^{\circ} \mathrm{C}$, while the blends prepared with cassava and corn starch exhibited the endotherm at $61^{\circ} \mathrm{C}$ and $61.5{ }^{\circ} \mathrm{C}$, respectively. Since the content of the crystalline component (PCL) was low $(20 \mathrm{wt} \%)$, the transitions were much less intense than in PCL. The continuous domain in the blends was plasticized starch, which probably caused the PCL crystals to be less packed and more heterogeneous, requiring less energy to melt [35]. Such a decrease in $\mathrm{T}_{\mathrm{m}}$ seems related to compatibility between PCL and plasticized starches, as corroborated by the shift in the infrared absorptions in the blends as discussed before. It is worth mentioning that starch is thought to interfere in the crystallization process of the PCL, causing changes in the packaging and quality of the PCL crystals in the blends. Table 2 reports thermal properties and crystallinity of the blends and PCL. As seen, the CIs calculated from Equation (1) for MaPS-PCL and CaPS-PCL were $62 \%$ and $38 \%$, respectively, indicating the crystallization of PCL was less affected by the presence of MaPS than CaPS, correlating with the infrared analysis in which a greater displacement in the absorption bands was found in blends with CaS than with MaS, due to the fact that $\mathrm{CaS}$ contained more amylopectin $(\sim 83 \%)$ than MaS ( 72\%). According to the literature, amylopectin has a branched structure and a much larger size than amylose, so the branched structure would probably interfere with the structural order of the PCL, manifesting itself in a low percentage of crystallinity.

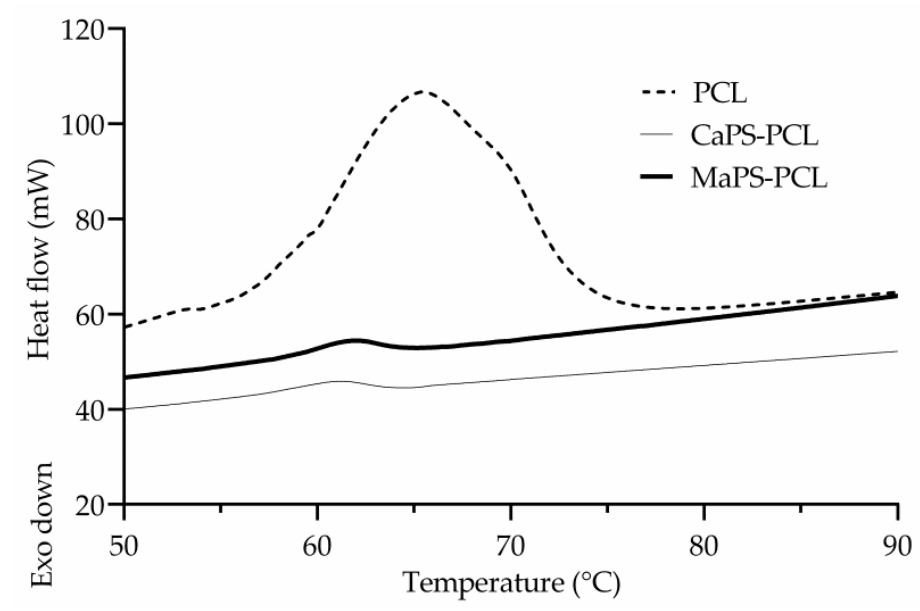

Figure 3. DSC thermograms of PCL, CaPS-PCL, and MaPS-PCL.

Table 2. Crystallization temperature $(\mathrm{Tc})$, melting enthalpy $(\Delta \mathrm{Hc})$, and percentage of crystallization $\left(\mathrm{C}_{\mathrm{I}}\right)$ of PCL, MaPS-PCL, and CaPS-PCL.

\begin{tabular}{cccccc}
\hline Sample & $\begin{array}{c}\mathbf{T}_{\mathbf{m}} \\
\left({ }^{\circ} \mathbf{C}\right)\end{array}$ & $\begin{array}{c}\Delta \mathbf{H}_{\mathbf{m}} \\
\left(\mathbf{J ~ g}^{-\mathbf{1}}\right)\end{array}$ & $\begin{array}{c}\mathbf{T}_{\mathbf{c}} \\
\left({ }^{\circ} \mathbf{C}\right)\end{array}$ & $\Delta_{\mathbf{H}_{\mathbf{c}}}(\mathbf{J} / \mathbf{g})$ & $\begin{array}{c}\mathbf{C}_{\mathbf{I}} \\
(\%)\end{array}$ \\
\hline CaPS-PCL & 61.0 & 10.0 & - & - & 38.0 \\
\hline MaPS-PCL & 61.5 & 16.5 & - & - & 62.0 \\
\hline PCL & 16.6 & 39.7 & 65.4 & 233 & 28.5 \\
\hline
\end{tabular}




\subsection{Thermal Stability}

Figure $4 \mathrm{a}, \mathrm{b}$ show the TGA traces of the plasticized starches of cassava and corn and the blends with PCL. The curves exhibit an initial weight loss between 10 and $150{ }^{\circ} \mathrm{C}$, corresponding to the evaporation of water and other volatiles present in the samples, in agreement with the literature [36]. Figure $4 \mathrm{c}, \mathrm{d}$ show the DTA traces of the plasticized cassava and corn starches and the blends with PCL. The transition at approximately $250{ }^{\circ} \mathrm{C}$ in CaPS and CaPS-PCL (Figure 4d) corresponds to the dissociation of the amylose chains at high temperatures, which led to the structural breakdown [37]. This transition was not observed in MaPS and MaPS-PCL. It is known that amylose can form complexes with some alcohols, such as 1-butanol [37], which increases the thermal stability of amylose due to the formation of strong molecular interactions that cause more energy to be required to break the bonds. It is believed that in the case of MaS, which contained more amylose than $\mathrm{CaS}$, an amylose-glycerol complex could have been generated, which increased the decomposition temperature of amylose, being reflected in a single transition in the thermogravimetric analysis, which corresponded to the decomposition of the amylose-glycerol complex and amylopectin.
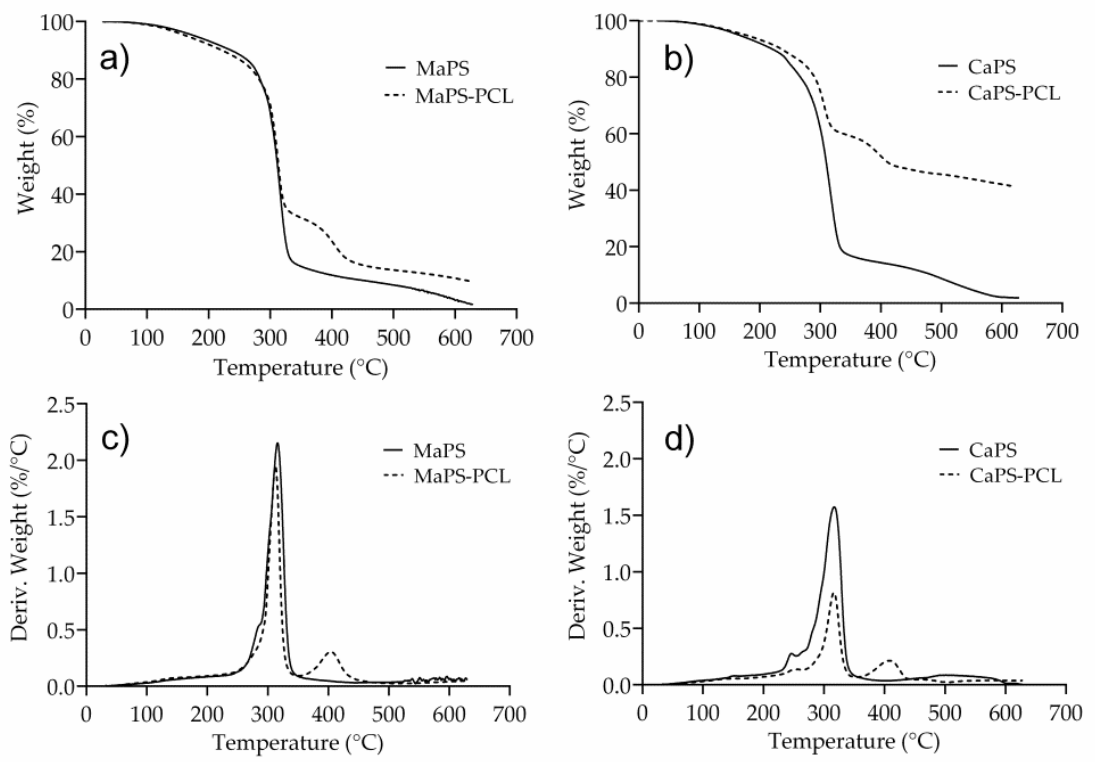

Figure 4. TGA traces of (a) MaPS and MaPS-PCL and (b) CaPS and CaPS-PCL. DTG traces of (c) MaPS and MaPS-PCL and (d) CaPS and CaPS-PCL.

The second decomposition event at $316^{\circ} \mathrm{C}$ roughly matched the decomposition of amylopectin in CaPS and CaPS-PCL or the amylose-glycerol and amylopectin complex (Figure 4d) in MaPS and MaPS-PCL (Figure 4c), representing, in all cases, a significant weight loss. For CaPS-PCL, the decomposition of the PCL occurred at $408^{\circ} \mathrm{C}$, while for MaPS-PCL, the starch degraded at $312{ }^{\circ} \mathrm{C}$ and PCL at $404^{\circ} \mathrm{C}$. Consequently, the incorporation of PCL in the thermoplastic starches did not affect the decomposition temperature profile of the starches; thus, CaPS and MaPS showed similar behavior with significant weight losses at the same temperatures.

\subsection{Dynamic Mechanical Analysis}

Figure 5 shows the effect of the incorporation of PCL on the viscosity of the blends with corn and cassava starch. As seen, PCL had a plasticizing action, since at a zero shear rate, MaPS and CaPS had a higher viscosity than the MaPS-PCL and CaPS-PCL blends. 


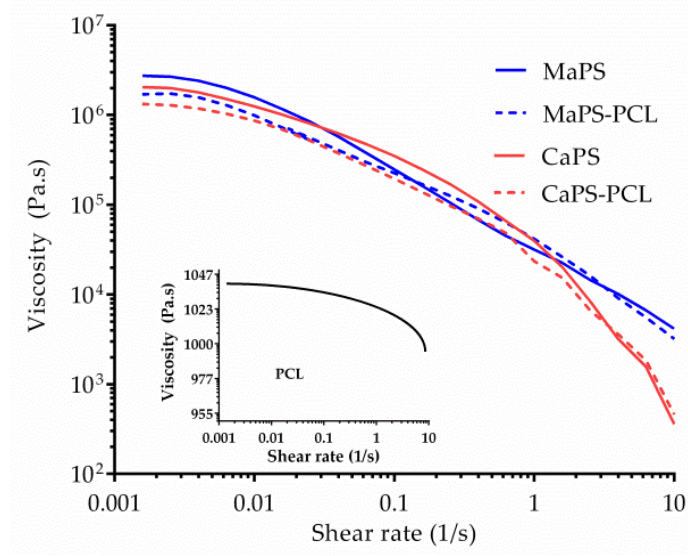

Figure 5. Viscosity of the starch composites as a function of shear rate at $130{ }^{\circ} \mathrm{C}$. Inset: viscosity of polycaprolactone under the same conditions.

To evaluate the influence of PCL on the thermal properties of thermoplastic starches, DSC and DMA were used. Because thermoplastic starches consist of two phases, one rich in starch and another rich in glycerol, transitions for both domains could be expected. Thus, the Tg corresponding to the glycerol-rich phase appeared at $-57^{\circ} \mathrm{C}$ for all materials including blends with PCL (Figure 6c). In this same temperature interval, the Tg of the PCL also appeared [38]; thus, there could be an overlap of both Tgs. On the other hand, the $\mathrm{Tg}$ corresponding to the phase rich in starch appeared at approximately $20^{\circ} \mathrm{C}$.
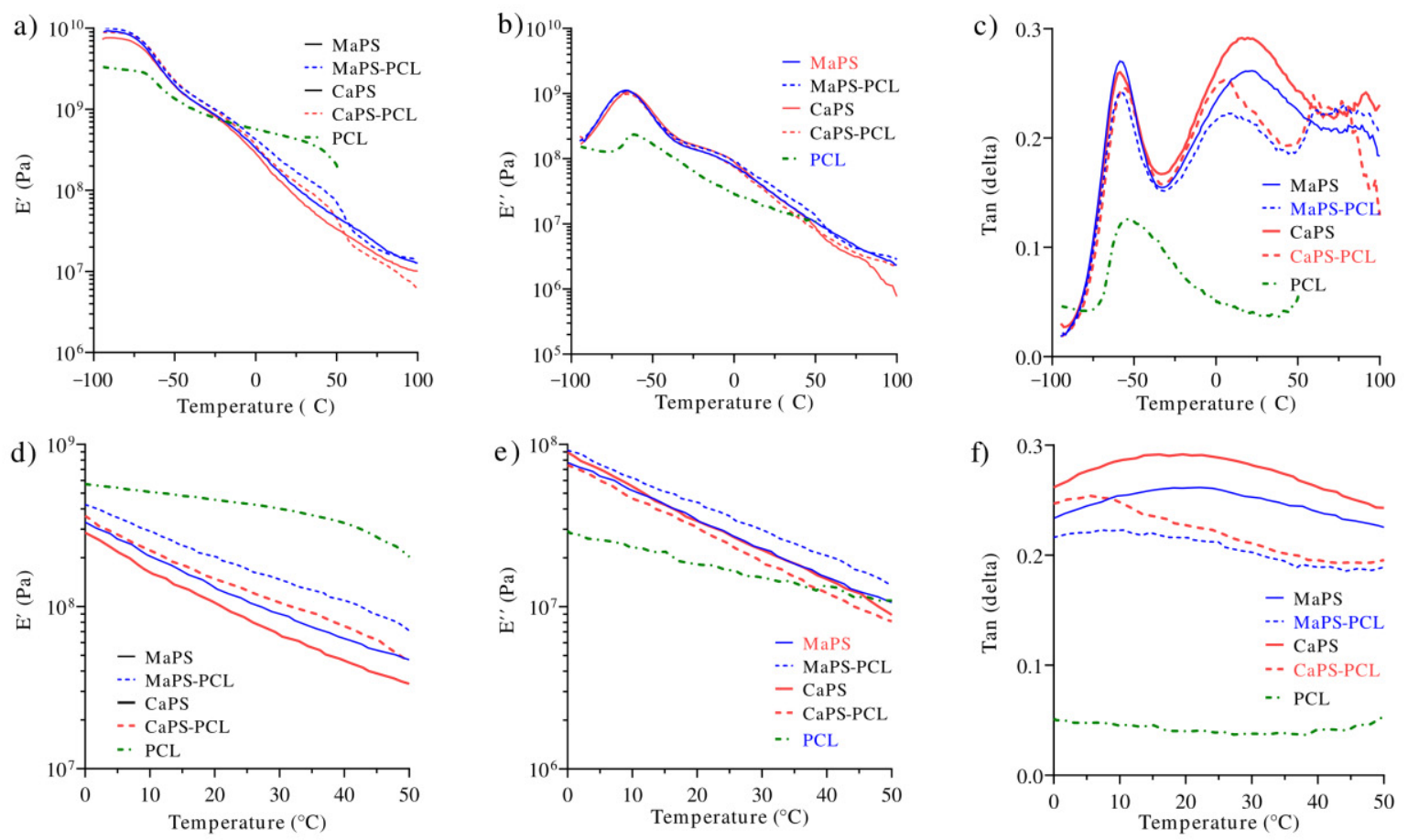

Figure 6. Loss factor (Tan delta) of the blends as a function of temperature.

The materials exhibited pseudoplastic behavior since the viscosity decreased with increasing shear deformation. Said flow behavior was also called shear thinning, which is associated with an increase in the degree of orientation of the polymeric molecules and the deterioration in the interlacing of chains, both in thermoplastic starches and PCL. Furthermore, the thermoplastic starches and the blends with PCL presented much higher viscosities than pure PCL (Figure 5). Correa et al. observed similar behavior in viscosity measurements made at 110 and $130{ }^{\circ} \mathrm{C}$ [36]. The addition of PCL in the 
thermoplastic starches caused a slight decrease in the blend viscosity, which resulted in the blends being slightly less viscous than the thermoplastic starch alone. The graph indicates that the plasticized cassava starch blended with PCL (CaPS-PCL) presented a slightly lower viscosity than the maize material (MaPS-PCL), probably explained in terms of the amylopectin content in the cassava starch. As observed by DSC, CaPS-PCL had a lower structural order, so it would be expected that the interactions would break down at lower temperatures than in the blend with cornstarch.

Figure 6a shows the storage modulus ( $\left.E^{\prime}\right)$ of the blends in a wide range of temperatures in which similar performances were observed for all of the blends. However, in the temperature range of $20-40{ }^{\circ} \mathrm{C}$, which is where the majority of practical applications occur (Figure 6d), the MaPS-PCL and CaPS-PCL blends were the ones with the highest rigidity, below the PCL, which decreased as the temperature increased. According to this, above $40{ }^{\circ} \mathrm{C}$, the material would not be functional for applications that require a polymer with greater rigidity.

Figure $6 \mathrm{~b}$ depicts the behavior of $\mathrm{E}^{\prime \prime}$, which was consistent with $\mathrm{E}^{\prime}$, indicating a similar behavior in all of the blends. In the range of $20-40{ }^{\circ} \mathrm{C}$ (Figure 6e), the blends did not present a significant difference, concluding that the application temperature of the materials should be between 20 and $40^{\circ} \mathrm{C}$ to achieve good mechanical performance.

In Figure $6 \mathrm{a}, \mathrm{c}$, transition was present at approximately $3{ }^{\circ} \mathrm{C}$ for MaPS-PCL and at $6^{\circ} \mathrm{C}$ for CaPS-PCL, which was only present in the blends of thermoplastic starch with PCL. It seemed to be caused by the formation of a more rigid component present in the blends, causing the appearance of transitions above $70^{\circ} \mathrm{C}$; however, further research is required to corroborate its structure and influence on blends.

\subsection{Mechanical Properties}

The mechanical properties of the CaPS and MaPS and CaPS-PCL and MaPS-PCL were evaluated by strain-stress tests. The tensile strength values reported as maximum tensile strength, $\sigma_{\max }$, and elongation at break are shown in Table 3.

Table 3. Tensile strength and percentage of elongation of the developed materials.

\begin{tabular}{ccccccc}
\hline Material & $\begin{array}{c}\boldsymbol{\sigma}_{\max } \\
(\mathbf{M P a})\end{array}$ & $\begin{array}{c}\text { Elongation } \\
(\mathbf{\%})\end{array}$ & Cases & Media & Standard Error & $\begin{array}{c}\text { Homogeneous } \\
\text { Groups }\end{array}$ \\
\hline MaPS & $0.210 \pm 0.019$ & 63 & 6 & 0.1642 & 0.010219 & $X$ \\
\hline CaPS & $0.164 \pm 0.005$ & 90 & 6 & 0.2101 & 0.010219 & $X$ \\
\hline MaPS-PCL & $0.168 \pm 0.003$ & 60 & 6 & 0.1680 & 0.010219 & $X$ \\
\hline CaPS-PCL & $0.227 \pm 0.040$ & 70 & 6 & 0.2272 & 0.010219 & $X$ \\
\hline
\end{tabular}

The method currently used to discriminate between means was the Fisher's least significant difference (LSD) procedure. With this method, there is a risk of $5.0 \%$ when saying that each pair of means is significantly different when the real difference is equal to 0 (Table 3).

A multiple comparison procedure was applied to determine which means were significantly different from others. Table 4 shows the estimated differences between each pair of means. The asterisk next to the four pairs indicates that these pairs showed statistically significant differences with a 95\% confidence level.

Multiple range tests were performed in Statgraphics, reporting the following results: The Kruskal-Wallis test evaluated the hypothesis that the medians of the tensile strength of the materials within each of the four levels of the compound were equal. Since $p<0.05$, there was a statistically significant difference among the medians with a $95 \%$ confidence level (Table 5). 
Table 4. Contrast between materials.

\begin{tabular}{cccc}
\hline Contrast & Significance & Difference & +/- Limits \\
\hline MaPS-MaPS-PCL & $*$ & 0.0421 & 0.0301 \\
\hline MaPS-CaPS & $*$ & 0.0458 & 0.0301 \\
\hline MaPS-CaPS-PCL & & -0.0171 & 0.0301 \\
\hline MaPS-CaPS & & 0.0037 & 0.0301 \\
\hline MaPS-PLC-CaPS-PCL & $*$ & -0.0592 & 0.0301 \\
\hline CaPS-MaPS-PCL & $*$ & -0.0629 & 0.0301 \\
\hline Significant difference. & & &
\end{tabular}

Table 5. Kruskal-Wallis test for the tensile strength of the materials.

\begin{tabular}{ccc}
\hline Material & Sample Size & Average \\
\hline MaPS & 6 & 17.16 \\
\hline MaPS-PCL & 6 & 8.50 \\
\hline CaPS & 6 & 6.50 \\
\hline CaPS-PCL & 6 & 17.83 \\
\hline Statistic $=12.2667, p$-value $=0.0065$. & &
\end{tabular}

The results indicate a significant difference in the blend tensile strength when corn or cassava starch was used and when including PCL in the blend. Probably, the susceptibility to water increased with the incorporation of PCL; however, this was not evaluated in the present work.

Other investigations have focused on plasticized starch, trying to modify some characteristics such as water absorption, resistance to tension, or modification of $\mathrm{Tg}$. Hernandez-Medina et al. reported that by acetylation, it was possible to decrease $\mathrm{Tg}$ and water absorption; however, tensile strength also decreased compared to natural TPS [8]. Mahieu et al. obtained blends of TPS with PCL of different molecular weights [39]; they found a decrease in deformation that was attributed to the lack of compatibility between the two components when $30 \mathrm{wt} \%$ PCL was used. In the case of Correa et al., various contents of PCL were blended with TPS, finding that the mechanical properties improved compared to pure TPS. In addition, because the blends are fully biodegradable, they can be used as vehicles for the controlled release of nutrients into the soil while they biodegrade [36]. As previously stated, the deformation of the TPS was not affected by the presence of PCL, since partial compatibility was found between the materials, at least with a load of $20 \mathrm{wt} \%$ of PCL.

It is worth mentioning that the retrogradation of starch in blends of TPS and PCL has been studied less thoroughly. In the work of Mina et al., in which $40-60 \mathrm{wt} \%$ of PCL was used, it was found that the blends were predominantly immiscible, considering that the incorporation of PCL in the retrogradation process of the blends was negligible [33]. However, due to the structure of starch and PCL, the formation of hydrogen bonds and secondary interactions that could intervene in the structural changes within the TPS would be expected.

TPSs are a new class of green polymers that can be disposed of after use without contamination. However, there are still some little-studied aspects that should be of importance in future research to create new products to serve human society. The limitations of the use of TPSs are their high sensitivity to moisture and retrogradation processes. Therefore, more studies are required for starch (i.e., native and modified) and plasticizers that focus on reducing water absorption and material retrogradation and, thus, obtaining materials with improved mechanical properties for various applications [40]. In this work, the properties exhibited by the blends can be useful for the manufacture of short-lived products such as disposable utensils and plates. 


\section{Conclusions}

In this work, bio-based blends derived from corn and cassava starch with PCL were developed. FTIR and calorimetry showed partial compatibility between thermoplastic starch and PCL, manifested by the shift of absorption signals and the melting temperature of PCL. Consequently, a better mechanical performance of the blends was attained. Thermogravimetric analysis showed evidence of the formation of an amylose-glycerol complex in blends with cornstarch that increased the decomposition temperature of amylase, moving to overlap with the decomposition temperature of amylopectin, presenting a single transition. Plasticized corn starch and cassava starch blended with PCL exhibited appropriate extrusion and injection processability and low susceptibility to water. Based on the present research, the next step is to quantify the decrease in the susceptibility to water of the blends, determine the biodegradability time under controlled conditions, in natural and accelerated weathering, to determine more precisely the performance of the blends in the design of single-use utensils such as cutlery and disposable plates.

\section{Patents}

Patent application MX/a/2020/011248. Biopolímeros y método para su preparación (Biopolymers and method for their preparation). By Anayansi Estrada-Monje, Sergio Alonso-Romero, and María Maldonado-Santoyo. October 2020.

Author Contributions: Formal analysis, S.A.-R., R.Z.-G., I.A.E.-M. and E.A.Z.-C.; Funding acquisition, A.E.-M.; Investigation, A.E.-M.; Methodology, A.E.-M., S.A.-R., R.Z.-G. and I.A.E.-M.; Supervision, A.E.-M.; Validation, I.A.E.-M.; Visualization, S.A.-R., R.Z.-G. and E.A.Z.-C.; Writing-original draft, A.E.-M.; Writing-review and editing, E.A.Z.-C. All authors have read and agreed to the published version of the manuscript.

Funding: The research was funded by the Secretaría de Innovación, Ciencia y Educación Superior del Estado de Guanajuato, México, through the Program Ecosistema de Innovación, Finnovateg-IDEA (Project: MC-CFINN1031).

Institutional Review Board Statement: Not applicable.

Informed Consent Statement: Not applicable.

Data Availability Statement: The data presented in this study are available on request from the corresponding author. The data are not publicly available due to privacy.

Acknowledgments: The authors wish to thank Claudia Hernández-Escobar for her helpful assistance during this research.

Conflicts of Interest: The authors declare no conflict of interest.

\section{References}

1. Heinrichs, S. Compromiso Mundial Para Reducir Los Plásticos de un Solo Uso. Available online: https://news.un.org/es/story/ 2019/03/1452961 (accessed on 15 March 2019).

2. Muhammad Shamsuddin, I. Bioplastics as Better Alternative to Petroplastics and Their Role in National Sustainability: A Review. Adv. Biosci. Bioeng. 2017, 5, 63. [CrossRef]

3. Kwon, S.; Zambrano, M.C.; Pawlak, J.J.; Venditti, R.A. Effect of lignocellulosic fiber composition on the aquatic biodegradation of wood pulps and the isolated cellulose, hemicellulose and lignin components: Kinetic modelling of the biodegradation process. Cellulose 2021, 28, 2863-2877. [CrossRef]

4. Leja, K.; Lewandowicz, G. Polymer biodegradation and biodegradable polymers-A review. Polish J. Environ. Stud. 2010, 19, 255-266.

5. Dordevic, D.; Necasova, L.; Antonic, B.; Jancikova, S.; Tremlová, B. Plastic cutlery alternative: Case study with biodegradable spoons. Foods 2021, 10, 1612. [CrossRef] [PubMed]

6. Hassan, M.M.; Le Guen, M.J.; Tucker, N.; Parker, K. Thermo-mechanical, morphological and water absorption properties of thermoplastic starch/cellulose composite foams reinforced with PLA. Cellulose 2019, 26, 4463-4478. [CrossRef]

7. Souza, R.C.R.; Andrade, C.T. Processing and properties of thermoplastic starch and its blends with sodium alginate. J. Appl. Polym. Sci. 2001, 81, 412-420. [CrossRef]

8. Hernández-Medina, M.; Torruco-Uco, J.G.; Chel-Guerrero, L.; Betancur-Ancona, D. Physical-chemical characterization of starch from cultivated tubers in Yucatan, Mexico. Cienc. Tecnol. Aliment. 2008, 28, 718-726. [CrossRef] 
9. Bertolini, A.C. Starches: Characterization, Properties, and Applications, 1st ed.; CRC Press: Boca Raton, FL, USA, 2009.

10. García, N.; Aranguren, M.; Dufresne, A.; Goyanes, S. Efecto de la concentración de amilopectina en la respuesta fisicomecánica de films de almidón. In Proceedings of the Congreso SAM/CONAMET 2007, San Nicolás, Buenos Aires, Argentina, 4-7 September 2007.

11. Rivadeneira-Velasco, K.E.; Utreras-Silva, C.A.; Díaz-Barrios, A.; Sommer-Márquez, A.E.; Tafur, J.P.; Michell, R.M. Green nanocomposites based on thermoplastic starch: A review. Polymers 2021, 13, 3227. [CrossRef] [PubMed]

12. Van Soest, J.J.G.; Vliegenthart, J.F.G. Crystallinity in starch plastics: Consequences for material properties. Trends Biotechnol. 1997, 15, 208-213. [CrossRef]

13. Averous, L.; Moro, L.; Dole, P.; Fringant, C. Properties of thermoplastic blends: Starch-polycaprolactone. Polymer 2000, 41, 4157-4167. [CrossRef]

14. Wang, J.; Liang, Y.; Zhang, Z.; Ye, C.; Chen, Y.; Wei, P.; Wang, Y.; Xia, Y. Thermoplastic starch plasticized by polymeric ionic liquid. Eur. Polym. J. 2021, 148, 110367. [CrossRef]

15. Abera, G.; Woldeyes, B.; Demash, H.D.; Miyake, G. The effect of plasticizers on thermoplastic starch films developed from the indigenous Ethiopian tuber crop Anchote (Coccinia abyssinica) starch. Int. J. Biol. Macromol. 2020, 155, 581-587. [CrossRef] [PubMed]

16. Giroto, A.S.; Garcia, R.H.S.; Colnago, L.A.; Klamczynski, A.; Glenn, G.M.; Ribeiro, C. Role of urea and melamine as synergic co-plasticizers for starch composites for fertilizer application. Int. J. Biol. Macromol. 2020, 144, 143-150. [CrossRef] [PubMed]

17. Hazrati, K.Z.; Sapuan, S.M.; Zuhri, M.Y.M.; Jumaidin, R. Effect of plasticizers on physical, thermal, and tensile properties of thermoplastic films based on Dioscorea hispida starch. Int. J. Biol. Macromol. 2021, 185, 219-228. [CrossRef] [PubMed]

18. Heidarian, P.; Behzad, T.; Sadeghi, M. Investigation of cross-linked PVA/starch biocomposites reinforced by cellulose nanofibrils isolated from aspen wood sawdust. Cellulose 2017, 24, 3323-3339. [CrossRef]

19. Lerma-Canto, A.; Gomez-Caturla, J.; Herrero-Herrero, M.; Garcia-Garcia, D.; Fombuena, V. Development of polylactic acid thermoplastic starch formulations using maleinized hemp oil as biobased plasticizer. Polymers 2021, 13, 1392. [CrossRef] [PubMed]

20. Balla, B.; Bartos, A.; Kun, D.; Csiszár, E.; Móczó, J.; Fekete, E. Improving mechanical and water sorption properties of thermoplastic starch by incorporating chitosan filler. Polym. Test. 2021, 101, 107278. [CrossRef]

21. Osman, A.F.; Siah, L.; Alrashdi, A.A.; Ul-Hamid, A.; Ibrahim, I. Improving the tensile and tear properties of thermoplastic starch/dolomite biocomposite film through sonication process. Polymers 2021, 13, 274. [CrossRef] [PubMed]

22. Carmona, V.B.; De Campos, A.; Marconcini, J.M.; Mattoso, L.H.C. Kinetics of thermal degradation applied to biocomposites with TPS, PCL and sisal fibers by non-isothermal procedures. J. Therm. Anal. Calorim. 2014, 115, 153-160. [CrossRef]

23. Dubois, P.; Krishnan, M.; Narayan, R. Aliphatic polyester-grafted starch-like polysaccharides by ring-opening polymerization. Polymer 1999, 40, 3091-3100. [CrossRef]

24. Carmona, V.B.; Corrêa, A.C.; Marconcini, J.M.; Mattoso, L.H.C. Properties of a Biodegradable Ternary Blend of Thermoplastic Starch (TPS), Poly( $\varepsilon$-Caprolactone) (PCL) and Poly(Lactic Acid) (PLA). J. Polym. Environ. 2015, 23, 83-89. [CrossRef]

25. Piñeros-Guerrero, N.; Piñeros-Castro, Y.; Ortega-Toro, R. Active biodegradable films based on thermoplastic starch and poly (E-caprolactone): Technological application of antioxidant extracts from rice husk. Rev. Mex. Ing. Quim. 2020, 19, 1095-1101. [CrossRef]

26. Hernandez, M.; Herminsul, J. Effect of the incorporation of polycaprolactone (PCL) on the retrogradation of binary blends with cassava thermoplastic starch (TPS). Polymers 2021, 13, 38. [CrossRef] [PubMed]

27. Cuevas-Carballo, Z.B.; Duarte-Aranda, S.; Canché-Escamilla, G. Properties and Biodegradability of Thermoplastic Starch Obtained from Granular Starches Grafted with Polycaprolactone. Int. J. Polym. Sci. 2017, 2017, 3975692. [CrossRef]

28. Crescenzi, V.; Manzini, G.; Calzolari, G.; Borri, C. Thermodynamics of fusion of poly- $\beta$-propiolactone and poly- $\epsilon$-caprolactone. comparative analysis of the melting of aliphatic polylactone and polyester chains. Eur. Polym. J. 1972, 8, 449-463. [CrossRef]

29. Vertuccio, L.; Gorrasi, G.; Sorrentino, A.; Vittoria, V. Nano clay reinforced PCL/starch blends obtained by high energy ball milling. Carbohydr. Polym. 2009, 75, 172-179. [CrossRef]

30. Moreno, O.; Cárdenas, J.; Atarés, L.; Chiralt, A. Influence of starch oxidation on the functionality of starch-gelatin based active films. Carbohydr. Polym. 2017, 178, 147-158. [CrossRef] [PubMed]

31. Zullo, R.; Iannace, S. The effects of different starch sources and plasticizers on film blowing of thermoplastic starch: Correlation among process, elongational properties and macromolecular structure. Carbohydr. Polym. 2009, 77, 376-383. [CrossRef]

32. Lomelí-Ramírez, M.G.; Barrios-Guzmán, A.J.; García-Enriquez, S.; Rivera-Prado, J.D.J.; Manríquez-González, R. Chemical and Mechanical Evaluation of Bio-composites Based on Thermoplastic Starch and Wood Particles Prepared by Thermal Compression. BioResources 2014, 9, 2960-2974. [CrossRef]

33. Mina, J.; Valadez, A.; Toledano, T. Physico-chemical studied of thermoplastic starch (TPS) and polycaprolactone (PCL). Biotecnol. Sect. Agropecu. Agroind. 2013, 11, 31-40.

34. Cesteros Iturbe, L.C. Aplicaciones de la FTIR al estudio de las interacciones polímero-polímero. Rev. Iberoam. Polímeros 2004, 5, 111-132.

35. Campos, A.; Teodoro, K.B.R.; Teixeira, E.M.; Corrêa, A.C.; Marconcini, J.M.; Wood, D.F.; Williams, T.G.; Mattoso, L.H.C. Properties of thermoplastic starch and TPS/polycaprolactone blend reinforced with sisal whiskers using extrusion processing. Polym. Eng. Sci. 2013, 53, 800-808. [CrossRef] 
36. Correa, A.C.; Carmona, V.B.; Simão, J.A.; Capparelli Mattoso, L.H.; Marconcini, J.M. Biodegradable blends of urea plasticized thermoplastic starch (UTPS) and poly( $\varepsilon$-caprolactone) (PCL): Morphological, rheological, thermal and mechanical properties. Carbohydr. Polym. 2017, 167, 177-184. [CrossRef] [PubMed]

37. Lemos, P.V.F.; Barbosa, L.S.; Ramos, I.G.; Coelho, R.E.; Druzian, J.I. Characterization of amylose and amylopectin fractions separated from potato, banana, corn, and cassava starches. Int. J. Biol. Macromol. 2019, 132, 32-42. [CrossRef] [PubMed]

38. Ninago, M.D.; López, O.V.; Lencina, M.M.S.; García, M.A.; Andreucetti, N.A.; Ciolino, A.E.; Villar, M.A. Enhancement of thermoplastic starch final properties by blending with poly( $\varepsilon$-caprolactone). Carbohydr. Polym. 2015, 134, 205-212. [CrossRef] [PubMed]

39. Mahieu, A.; Terrié, C.; Agoulon, A.; Leblanc, N.; Youssef, B. Thermoplastic starch and poly( $\varepsilon$-caprolactone) blends: Morphology and mechanical properties as a function of relative humidity. J. Polym. Res. 2013, 20, 229. [CrossRef]

40. Nafchi, A.M.; Moradpour, M.; Saeidi, M.; Alias, A.K. Thermoplastic starches: Properties, challenges, and prospects. Starch-Staerke 2013, 65, 61-72. [CrossRef] 